\title{
Evaluation of relative yeast cell surface hydrophobicity measured by flow cytometry
}

\author{
LISA COLLING, RICHARD N. CARTER, MICHAEL ESSMANN, \& BRYAN LARSEN \\ Infectious Disease Research Laboratory, Des Moines University, Des Moines, IA, USA
}

(Received 9 fune 2004; accepted 9 November 2004)

\begin{abstract}
Objective: To develop an efficient method for evaluating cell surface hydrophobicity and to apply the method to demonstrate the effects of fungal growth conditions on cell surface properties.

Methods: Yeast isolates were suspended in phosphate-buffered saline and mixed with deep blue-dyed polystyrene microspheres. Flow cytometry was used to detect the degree of microsphere binding to yeast cells. Different strains of yeast were compared for intrinsic microsphere binding activity and changes in growth conditions were invoked to modify the relative surface hydrophobicity.

Results: Commercially available blue-dyed polystyrene microspheres showed strong fluorescence in the FL3 channel, whereas yeast cells did not show appreciable FL3 fluorescence. Microspheres and yeast were generally distinguishable on the basis of size revealed by forward light scatter. This method showed a wide variation in intrinsic cell surface hydrophobicity among Candida albicans strains. Likewise, variation in hydrophobicity of non-albicans yeast species was observed. Growth on solid media, incubation at $25^{\circ} \mathrm{C}$, or $250 \mathrm{mg} / \mathrm{dl}$ glucose concentration increased hydrophobicity compared with growth in liquid media, incubation at $37^{\circ} \mathrm{C}$, or $50 \mathrm{mg} / \mathrm{dl}$ glucose, respectively. Growth in $1 \times 10^{-9} \mathrm{M}$ estradiol had no appreciable effect on hydrophobicity.

Conclusions: Stained latex microspheres fluoresced in the FL3 channel of the flow cytometer and bound to yeast cells to an extent related to the surface hydrophobicity of the yeast. Binding detected by flow cytometry showed that clinical yeast isolates varied in intrinsic binding capacity and this binding ability was altered by different growth conditions. The implications for virulence regulation among yeast isolates are discussed.
\end{abstract}

Keywords: Virulence, Candida, adherence

\section{Introduction}

It is well recognized that mucosal pathogens depend on attachment to tissue substrates as part of the colonization and pathogenic processes. The adherence properties of Candida are of special interest because the organism attaches both to tissues and to medical devices. The ability of Candida to attach to plastics may be exploited in studying its interaction with surfaces [1-4]. Because Candida is a constituent of the normal flora, its relation to the host is at times benign and at times pathogenic; this situation may be the result of the ability of the organism to regulate virulence properties under varying environmental conditions.

Attachment of microorganisms to tissues is complex, involving both specific receptor molecules and non-specific physical and chemical surface properties $[5,6]$. Researchers have previously engaged in studies attempting to identify molecules on the surface of microorganisms, since these substances are the most likely to be engaged in interaction with host tissues and the most likely to contribute to physical interactions (such as hydrophobicity); and because these surface adhesive factors contribute to virulence by binding the microorganism to tissues. Antifungal factors such as antibodies would probably bind to and interfere with the function of such surface molecules [7], leading to the quest to better understand which surface properties contribute to tissue adherence.

Among the various mechanisms for microbial adherence, cell surface hydrophobicity is one of the apparently important contributors in attachment of

Correspondence: Bryan Larsen, Des Moines University, 3200 Grand Avenue, Des Moines, IA, 50312, USA. Tel: 515-271-1559. Fax: 515-271-1644. E-mail: bryan.larsen@dmu.edu

ISSN 1064-7449 print/ISSN 1098-0997 online (C) 2005 Taylor \& Francis Group Ltd DOI: $10.1080 / 10647440400028169$ 
yeast to tissue or to medical devices $[8,9]$. Consequently, research on the virulence of Candida should include assessment of the intrinsic relative hydrophobicity of the organism and the modulation of hydrophobicity under various conditions. Several methods have been used to measure hydrophobicity, including contact angles, partitioning into organic solvents and attachment to hydrophobic surfaces [10]. Of these, attachment to styrene is the most straightforward method. For example, measurement of contact angles requires sophisticated equipment that is not usually found in a standard infectious disease laboratory, and partitioning of organisms into aqueous and organic solvents is nearly impossible with fungal cells because they are so much heavier than bacteria that they tend to fall out of suspension very quickly. Binding of styrene microspheres has therefore become an attractive alternative to contact angle or solvent portioning. However, microscopic evaluation of the binding of styrene microspheres to yeast cells requires skilled observation, judgment regarding aggregates of microspheres and yeast, and considerable time to develop statistically adequate numbers of observations. For these reasons, we developed a flow cytometry approach to analyze styrene microsphere attachment to yeast cells.

\section{Methods}

Yeast strains

The Des Moines University Infectious Disease Research Laboratory maintains a collection of 80 strains of Candida albicans and ATCC strains of Candida glabrata (2001,660321), Candida albicans $(10231,36232)$, and Saccharomyces cerevisiae $(9763,4098)$. Strains are maintained on Sabouraud dextrose (SAB) agar at $4^{\circ} \mathrm{C}$ and are subcultured at 3month intervals. Each strain in the collection was previously tested for the effect of estradiol $(1.0 \mathrm{x}$ $\left.10^{-9} \mathrm{M}\right)$ on growth, for production of colony outgrowth on spider medium [11], and susceptibility to fluconazole by NCCLS methods. A subset of the culture collection was selected, and strains used in this study are listed in Table I. Before use, each organism was subcultured on SAB agar for $48 \mathrm{~h}$ unless otherwise noted.

\section{Styrene microspheres}

Styrene beads, $0.834 \mu \mathrm{M}$, dyed deep blue, were obtained from Sigma Chemical Company (St. Louis, MO, USA ). Beads were provided in $1 \mathrm{ml}$ suspension ( $10 \%$ solids), with the subsequent addition of $3 \mathrm{ml}$ distilled water. For bead adherence tests, microsphere suspensions were vigorously mixed and $10 \mu \mathrm{l}$ of the bead suspension added to a 1:100 dilution of a yeast suspension in phosphate buffer saline (PBS). The yeast suspension was prepared by dispersing colonial growth from $\mathrm{SAB}$ medium into PBS and diluting to an optical density of $1.0 \pm 0.1 \mathrm{AU}$ at $600 \mathrm{~nm}$. Beads and yeast were allowed to interact at room temperature for $30 \mathrm{~min}$ on a rotator at 14 cycles per min. Subsequently, each sample was vortexed vigorously and analyzed by flow cytometry.

Table I. Characteristics of yeast strains used in this study.

\begin{tabular}{|c|c|c|c|c|}
\hline Species & Strain & $\begin{array}{l}\text { Growth in estradiol } \\
\text { medium }^{1}\end{array}$ & Growth in spider medium & Fluconazole susceptibility \\
\hline \multirow{12}{*}{$\begin{array}{l}\text { Candida albicans } \\
\text { clinical isolates }\end{array}$} & GT 188 & 0.1 & - & $\mathrm{S}$ \\
\hline & GT 132 & 0.14 & - & $\mathrm{S}$ \\
\hline & 986 & 0.26 & - & $\mathrm{R}$ \\
\hline & $875 G$ & 0.27 & + & $S$ \\
\hline & 980 & 0.3 & + & $\mathrm{R}$ \\
\hline & 984 & 0.3 & - & $\mathrm{R}$ \\
\hline & GT 148 & 4.87 & + & $S$ \\
\hline & 9495 & 5.09 & + & $\mathrm{S}$ \\
\hline & GT 387 & 6.13 & - & $S$ \\
\hline & 397 & 8.6 & + & $S$ \\
\hline & GT 142 & 12.4 & - & $S$ \\
\hline & 232 & 1.31 & + & $\mathrm{S}$ \\
\hline \multirow[t]{2}{*}{ ATCC Candida albicans } & 10231 & 1.94 & + & S \\
\hline & 36232 & 2.25 & - & S \\
\hline \multirow[t]{2}{*}{ ATCC Candida glabrata } & 2001 & NT & NT & NT \\
\hline & 660321 & NT & NT & NT \\
\hline \multirow[t]{2}{*}{ ATCC $S$. cerevisiae } & 9763 & 1.14 & - & S \\
\hline & 4098 & 1.86 & - & $\mathrm{S}$ \\
\hline
\end{tabular}

${ }^{1}$ Relative growth in estradiol involved yeast nitrogen broth media with and without estradiol. Cultures were plated quantitatively after $12 \mathrm{~h}$ of growth. Results are expressed as counts in estradiol medium/counts in control medium. NT, not tested; S, susceptible; R, resistant. 
Flow cytometry

Flow cytometry employed a Becton Dickenson FAC scan instrument. For each sample analyzed we recorded forward scatter (FSC) and side scatter (SSC), each with linear amplification. We also recorded data from fluorescence channel 3 (FL3h) with logarithmic amplification. Unless otherwise noted, 10000 events were collected for each sample. For each sample an FSC/SSC plot was used to monitor the geometry of particles in the sample. A histogram plot of events collected versus FL3-h was also recorded. A marker (M1) was placed on FL3 histograms to identify events above the fluorescence threshold, and statistics derived from the histogram included the mean FL3 channel fluorescence.

\section{Statistics}

All data collected represented continuous variables (\% M1 and mean channel fluorescence) and were evaluated by paired comparisons using Student's $t$ test; $p<0.05$ was considered significant.

\section{Results}

Deep blue-dyed styrene microspheres have previously been used for the microscopic evaluation of yeast hydrophobicity. However, their use as probes for flow cytometry depends on the ability of the flow cytometer to detect and distinguish microspheres from yeast cells. We first determined whether the beads were fluorescent. Figure 1 shows that FL3 detected the microspheres, but none of the other
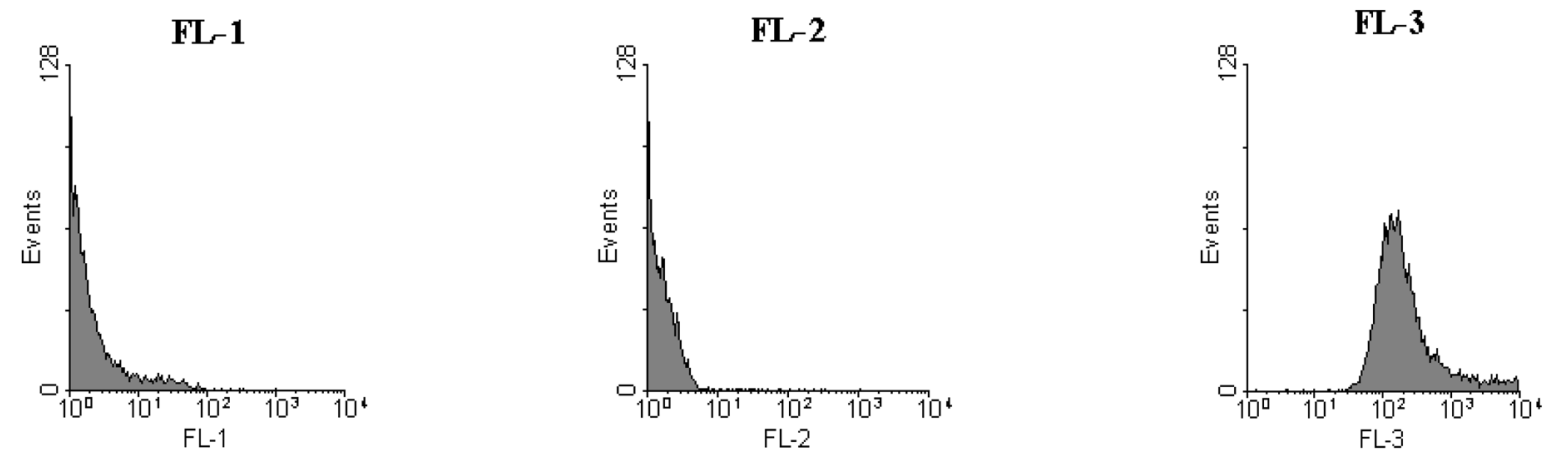

Figure 1. Dyed styrene microspheres were evaluated by flow cytometry. The fluorescence of these microspheres appears in fluorescence channel 3 (FL3), but not in FL1 or FL2.
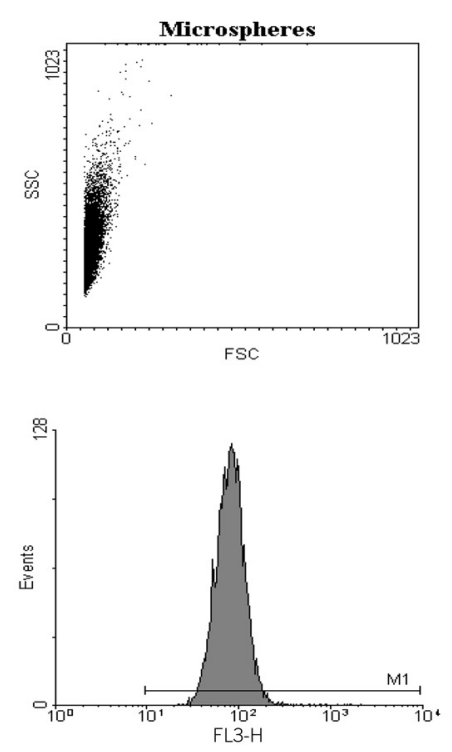
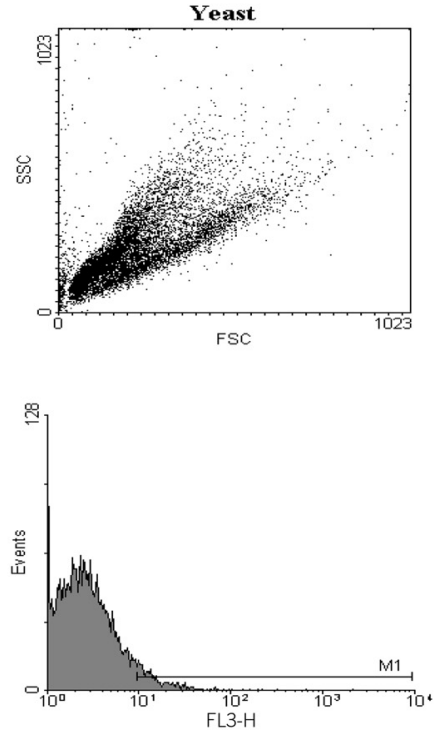
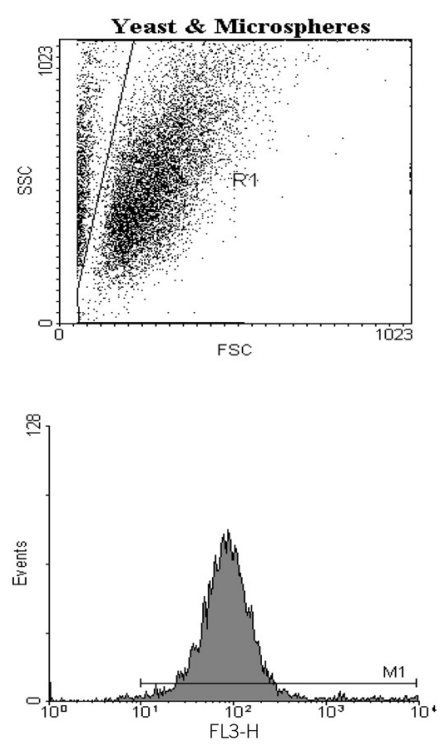

Figure 2. Flow cytometry is used to distinguish yeasts, dyed styrene microspheres, and yeasts to which styrene microspheres are bound. The geometry of the particles (yeasts or microspheres) is illustrated in the upper three panels. Microspheres showed a smaller forward scatter signal than yeasts. When yeasts that have interacted with microspheres are gated (polygon in upper right panel) they produce a strong FL3 signal (lower right panel) due to microsphere attachment. A marker (M1) is used to define fluorescent and non-fluorescent events. The relative fluorescence of each population is indicated by mean channel fluorescence, which is calculated from the histograms (lower panels). 
fluorescence channels did so. Therefore, the FL3 signal for each subsequent experiment was recorded.

To determine whether yeast and styrene microspheres could be distinguished by flow cytometry, we analyzed the FSC/SSC patterns in relation to FL3 fluorescence for yeast alone, for microspheres alone, and for a combination of yeast and microspheres. Figure 2 shows that the yeast cells, which are generally 2 to $5 \mu \mathrm{M}$ in diameter, were clearly distinguishable from microspheres (sub-micrometer size) on the basis of particle geometry (FSC/SSC). The yeast cells, which do not fluoresce in the FL3 channel, showed fluorescence only when microspheres were allowed to interact with them. We were able to apply a gate (as shown in Figure 2) to the yeast/microsphere mixtures in order to remove fluorescence associated with unbound microspheres.

On the basis of these observations, we were able to evaluate the intrinsic cell surface hydrophobicity implied by microsphere binding to yeast. Twelve clinical isolates of Candida albicans and six ATCC yeast strains were grown on SAB agar and evaluated for microsphere binding capacity. Table II summarizes the results, which indicate that both the percentage of M1 and mean channel fluorescence (FL3) vary among strains.

Having observed the intrinsic hydrophobicity of these test organisms, we then investigated whether changes in environmental and growth conditions could alter the hydrophobicity of these yeasts. A series of studies evaluated differences in growth temperatures, growth in liquid medium versus solid medium, glucose concentrations, and growth in the presence of various concentrations of estradiol, in relation to cell surface hydrophobicity.

The results, shown in Table III, indicate that yeasts grown in submerged (liquid) culture were

Table II. Intrinsic hydrophobicity of 18 fungal strains.

\begin{tabular}{lccc}
\hline Species & Strain & $\% \mathrm{M} 1^{\star}$ & $\mathrm{MCF}^{\star}$ \\
\hline Candida albicans clinical isolates & GT 188 & 97.42 & 211.66 \\
& GT 132 & 99.86 & 260.84 \\
& 986 & 97.26 & 169.58 \\
& $875 \mathrm{G}$ & 98.79 & 202.56 \\
& 980 & 98.74 & 381.58 \\
& 984 & 98.36 & 190.31 \\
& GT 148 & 87.31 & 179.78 \\
& 9495 & 78.71 & 137.88 \\
& GT 387 & 99.16 & 217.62 \\
& 397 & 97.93 & 174.25 \\
Mean for all clinical isolates & GT 142 & 93.97 & 207.17 \\
ATCC Candida albicans & 232 & 98.88 & 237.49 \\
& 10231 & 95.53 & 214.22 \\
ATCC Candida glabrata & 36232 & 67.42 & 143.12 \\
& 2001 & 77.97 & 239.85 \\
ATCC Saccharomyces cerevisiae & 960321 & 99.53 & 144.67 \\
Mean for ATCC organisms & 4098 & 99.61 & 477.40 \\
\hline
\end{tabular}

* Mean channel fluorescence for FL3; increasing \%M1 numbers indicate higher percentage of yeast cells having any beads attached, whereas MCF for FL3 indicates the relative number of beads attached per yeast cell.

Table III. Effect of environmental conditions on yeast hydrophobicity.

\begin{tabular}{|c|c|c|c|c|c|c|}
\hline & $\% \mathrm{M} 1^{\star}$ & SD & $p$ Value & Mean FL3* & SD & $p$ Value \\
\hline $\begin{array}{l}\text { Growth on solid } \\
\text { agar media }\end{array}$ & 88.62 & 11.31 & & 206.42 & 81.68 & \\
\hline $\begin{array}{l}\text { Growth in liquid } \\
\text { media }\end{array}$ & 74.84 & 12.99 & 0.00005 & 166.22 & 110.10 & 0.13054 \\
\hline Growth at $25^{\circ} \mathrm{C}$ & 88.38 & 12.34 & & 186.33 & 70.21 & \\
\hline $\begin{array}{l}\text { Growth at } 37^{\circ} \mathrm{C} \\
\text { Glucose } \\
\text { concentration }\end{array}$ & 67.31 & 18.88 & 0.0006 & 153.61 & 107.57 & 0.05463 \\
\hline $0 \mathrm{mg} / 100 \mathrm{ml}$ & 88.2 & 12.31 & & 165.04 & 76.84 & \\
\hline $50 \mathrm{mg} / 100 \mathrm{ml}$ & 89.72 & 10.64 & 0.2091 & 188.85 & 81.81 & 0.00313 \\
\hline $100 \mathrm{mg} / 100 \mathrm{ml}$ & 91.92 & 8.78 & 0.0113 & 198.92 & 81.03 & 0.01376 \\
\hline $250 \mathrm{mg} / 100 \mathrm{ml}$ & 92.92 & 8.54 & 0.0128 & 213.05 & 85.65 & 0.00003 \\
\hline $\begin{array}{l}500 \mathrm{mg} / 100 \mathrm{ml} \\
17 \beta \text {-estradiol } \\
\text { concentration }(\mathrm{M})\end{array}$ & 93.53 & 7.92 & 0.0191 & 208.33 & 87.44 & 0.00011 \\
\hline 0 & 84.96 & 13.25 & & 214.48 & 105.40 & \\
\hline $10^{-9}$ & 85.40 & 14.09 & 0.891 & 176.38 & 54.94 & 0.120 \\
\hline $10^{-8}$ & 90.84 & 11.13 & 0.001 & 266.58 & 292.72 & 0.472 \\
\hline $10^{-7}$ & 94.88 & 5.58 & 0.004 & 333.60 & 110.64 & 0.001 \\
\hline $10^{-6}$ & 86.92 & 13.12 & 0.166 & 214.91 & 83.51 & 0.978 \\
\hline
\end{tabular}

$\mathrm{SD}$, standard deviation; ${ }^{\star}$ mean channel fluorescence for FL3. Increasing $\% \mathrm{M} 1$ numbers indicate higher percentage of yeast cells having any beads attached, whereas MCF for FL3 indicates the relative number of beads attached per yeast cell. Average for all 18 strains tested. 
consistently less hydrophobic than those grown on semi-solid media. In addition, growth at $25^{\circ} \mathrm{C}$ versus $37^{\circ} \mathrm{C}$ was associated with greater relative hydrophobicity. Glucose concentrations ranging from levels potentially reflecting hypoglycemia to those potentially reflecting hyperglycemia were also tested. Higher glucose levels were associated with increased hydrophobicity. Whereas $17 \beta$-estradiol has been shown to affect growth of Candida, it did not have an appreciable effect on hydrophobicity except at $1 \mathrm{x}$ $10^{-7}$ M $17 \beta$-estradiol.

\section{Discussion}

Because Candida albicans is the fourth most common nosocomial pathogen and frequently causes mucosal infections such as vaginal candidiasis, its virulence properties are of interest. In particular, understanding what environmental conditions result in a change from colonization to symptomatic infection may be critical in understanding mucocutaneous infections. We have focused on hydrophobicity as one of the putatively important virulence attributes of Candida albicans. The key contributions of Hazen's $[1,9,10]$ group have underscored the importance of hydrophobicity in microbial virulence and suggest that studies involving hydrophobicity, although not addressing all known fungal virulence attributes, will probably refer to both binding to tissues as well as binding to phagocytic cells. We attempted to develop a simple method for evaluating the relative cell surface hydrophobicity of yeast by means of flow cytometry. This new method is reported and its use in identifying environmental conditions that affect cell surface hydrophobicity is summarized.

Hydrophobicity of microbial surfaces is a potential contributor to the adherence of yeast to tissue or medical materials, but is probably not the only factor involved. For example, specific ligands for extracellular matrix substances have been identified [12]. Adherence to surfaces such as catheters may, in addition to hydrophobicity, depend on the production of biofilm [13, 14]. Therefore, cell surface hydrophobicity alone may not predict how likely an organism is to attach to tissues. However, the method we describe can be used to provide a measure of an organism's intrinsic affinity for hydrophobic surfaces, and this affinity has been reported to have at least some relationship to virulence [5].

Perhaps of greater interest among our findings is the fact that different species and different strains of yeast displayed variable levels of hydrophobicity. Other authors have also noted that epithelial colonization was variable [15], as was adherence to surfaces [16]. Different adherence assays reflect a particular set of physical and chemical interactions with substrates; some authors have examined yeast adherence to buccal epithelium $[17,18]$ or cultured enterocytes [19], whereas others, including ourselves, have focused on inanimate particles. However, none of these assays are known to predict binding to vaginal epithelium. As a result, such binding studies will need to be the subject of future research.

Regardless of the relationship of microsphere binding to vaginal epithelial adherence, our method is able to assess how different growth and incubation conditions influence the intrinsic cell surface hydrophobicity of our test organisms. We observed that, although yeasts varied in their intrinsic cell surface hydrophobicity, most environmental conditions tested affected yeasts in a consistent manner. For example, growth on a semi-solid medium always produced cells that bound more microspheres than cells grown in submerged culture. Cells grown at ambient temperature were consistently more hydrophobic than cells grown at $37^{\circ} \mathrm{C}$. Increasing glucose concentrations seemed to modestly increase relative hydrophobicity.

Observations on growth at $25^{\circ} \mathrm{C}$ and $37^{\circ} \mathrm{C}$ agree with reports in the literature for both yeasts and some bacteria $[8,20-23]$. Comparison with glucose findings in the literature is complex because different concentrations of glucose were studied and a variety of adherence assays were performed [13, 14, 24, 25]. However, biofilm formation is certainly enhanced by very high glucose concentrations [14]. We limited our studies to concentrations of glucose that might be observed in healthy and in diabetic individuals. This approach was also followed by Hostetter's group $[25,26]$, who found that another putative virulence factor, iC3b analog, was increased in high glucose states.

The current study lays the groundwork for a more comprehensive evaluation of conditions that can alter cell hydrophobicity or of reagents that may interfere with the binding of yeasts to tissue sites. Adhesive factors continue to represent an opportunity for novel anti-microbials and, at the same time, represent a target less studied than molecular targets related to cellular biosynthetic mechanisms.

\section{References}

1. Hazen KC, Hazen BW. A simple polystyrene microsphere assay for detecting cell surface hydrophobicity heterogeneity with Candida albicans populations. J Microbiol 1987;6:289.

2. Klotz SA, Drutz DJ, Zajic JE. Factors governing adherence of Candida species to plastic surfaces. Infect Immun 1985;50:97101.

3. Panagoda GJ, Ellepola AN, Samaranayake LP. Adhesion to denture acrylic surfaces and relative cell-surface hydrophobicity of Candida parapsilosis and Candida albicans. APMIS 1998;106:736-742. 
4. Waltimo T, Vallittu P, Haapasalo M. Adherence of Candida species to newly polymerized and water-stored denture base polymers. Int J Prosthodont 2001;14:457-460.

5. Masuoka J, Hazen KC. Cell wall protein mannosylation determines Candida albicans cell surface hydrophobicity. Microbiology 1997;143:3015-3021.

6. Sundstrom P. Adhesion in Candida species. Cell Microbiol 2002;4:461-469.

7. Alberti-Segui C, Morales AJ, Xing H, et al. Identification of potential cell-surface proteins in Candida albicans and investigation of the role of a putative cell-surface glycosidase in adhesion and virulence. Yeast 2004;21:285-302.

8. Blanco MT, Blanco J, Sanchez-Benito R, et al. Incubation temperatures affect adherence to plastic of Candida albicans by changing the cellular surface hydrophobicity. Microbios 1997;89:23-28.

9. Hazen KC, Brawner DL, Riesselman MH, Jutila MA, Cutler JE. Differential adherence of hydrophobic and hydrophilic Candida albicans yeast cells to mouse tissues. Infect Immun 1991;59:907-912.

10. Hazen BW, Hazen KC. Modification and application of a simple, surface hydrophobicity detection method to immune cells. J Immunol Methods 1988;107:157-163.

11. Liu H, Kohler J, Fink GR. Suppression of hyphal formation in Candida albicans by mutation of a STE12 homolog. Science 1994;266:1723-1726.

12. Alonso R, Llopis I, Flores C, Murgui A, Timoneda J. Different adhesions for type IV collagen on Candida albicans: identification of a lectin-like adhesion recognizing the 7S(IV) domain. Microbiology 2001;147:1971-1981.

13. Hawser SP, Douglas LJ. Biofilm formation by Candida species on the surface of catheter materials in vitro. Infect Immun 1994;62:915-921.

14. Shin JH, Kee Sj, Shin MG, et al. Biofilm production by isolates of Candida species recovered from nonneutropenic patients: comparison of bloodstream isolates with isolates from other sources. J Clin Microbiol 2002;40:1244-1248.

15. Mellado E, Cuenca-Estrella M, Regadera J, Gonzalez M, Diaz-Guerra TM, Rodriguez-Tudela JL. Sustained gastrointestinal colonization and systemic dissemination by Candida albicans, Candida tropicalis and Candida parapsilosis in adult mice. Diagn Microbiol Infect Dis 2000;38:21-28.
16. Luo G, Samaranayake LP. Candida glabrata, an emerging fungal pathogen, exhibits superior relative cell surface hydrophobicity and adhesion to denture acrylic surfaces compared with Candida albicans. APMIS 2002;110:601-610.

17. Biasoli MS, Tosello ME, Magaro HM. Adherence of Candida strains isolated from the human gastrointestinal tract. Mycoses 2002;45:465-469.

18. Samaranayake YH, Samaranayake LP, Yau JY, Ellepola AN, Anil S, Yeung KW. Adhesion and cell-surface hydrophobicity of sequentially isolated genetic isotypes of Candida albicans in an HIV-infected Southern Chinese cohort. Mycoses 2003;46:375-383.

19. Wiesner SM, Bendel CM, Hess DJ, Erlandsen SL, Wells CL. Adherence of yeast and filamentous forms of Candida albican to cultured enterocytes. Crit Care Med 2002;30:677-683.

20. Jabra-Rizk MA, Falkler Jr WA, Merz WG, Meiller TF. New assay for measuring cell surface hydrophobicities of Candida dubliniensis and Candida albicans. Clin Diagn Lab Immunol 2001;8:585-587.

21. Jana TK, Srivastava AK, Csery K, Arora DK. Influence of growth and environmental conditions on cell surface hydrophobicity of Pseudomonas fluorescens in non-specific adhesion. Can J Microbiol 2000;46:28-37.

22. Mikucka A, Gospodarek E, Ulatowska B. Influence of culture conditions on cell surface hydrophobicity of rods of genus Serratia. Med Dosw Mikrobiol 2000;52:9-15.

23. Wolska K, Pogorzelska S, Fijol E, Jakubczak A, Bukowski K. The effect of culture conditions on hydrophobic properties of Pseudomonas aeruginosa. Med Dosw Mikrobiol 2002;54:61-6.

24. Fan J, Chaturvedi V, Shen SH. Identification and phylogenetic analysis of a glucose transporter gene family from the human pathogenic yeast Candida albicans. J Mol Evol 2002;55:336-346.

25. Gustafson KS, Vercellotti GM, Bendel CM, Hostetter MK. Molecular mimicry in Candida albicans. Role of integrin analogue in adhesion of the yeast to human endothelium. J Clin Invest 1991;87:1896-1902.

26. Gilmore BJ, Retsinas EM, Lorenz JS, Hostetter MK. An iC3b receptor on Candida albicans: structure, function, and correlates for pathogenicity. J Infect Dis 1988;157:38-46. 


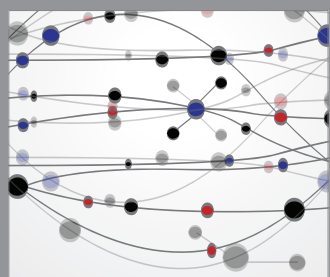

The Scientific World Journal
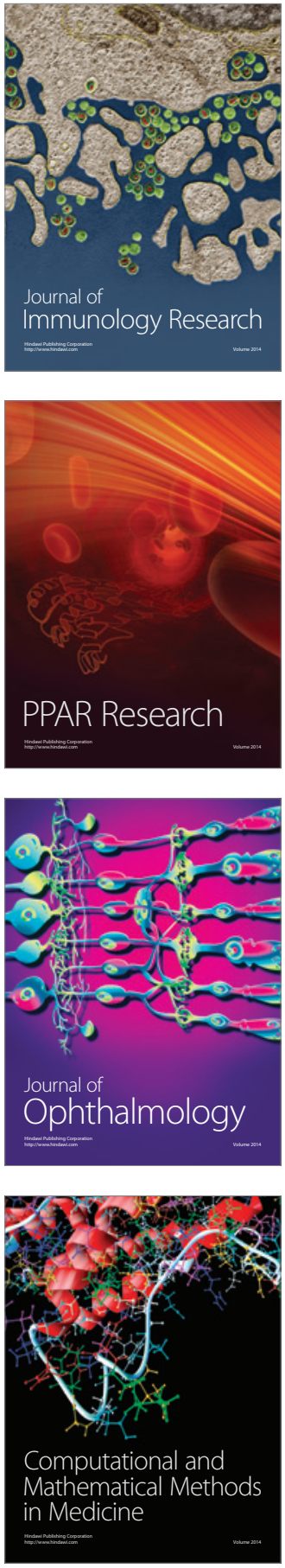

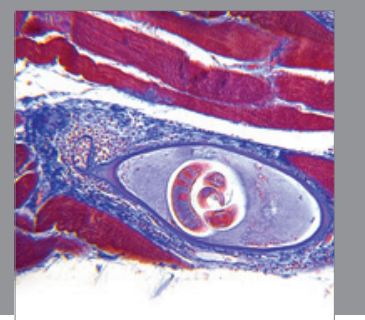

Gastroenterology

Research and Practice
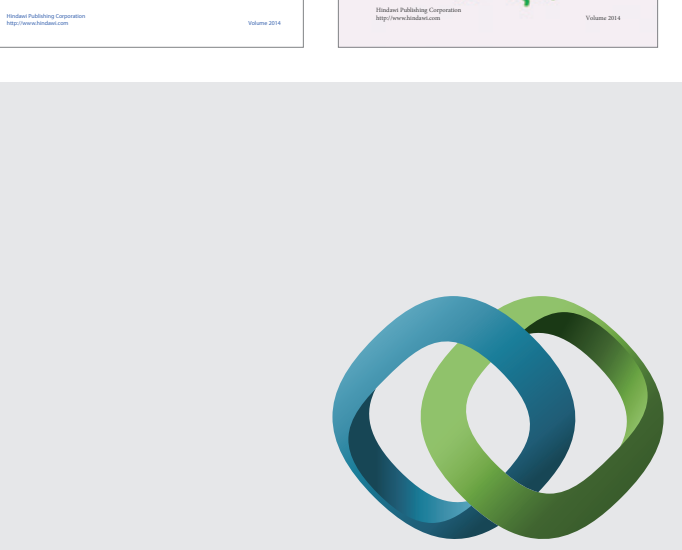

\section{Hindawi}

Submit your manuscripts at

http://www.hindawi.com
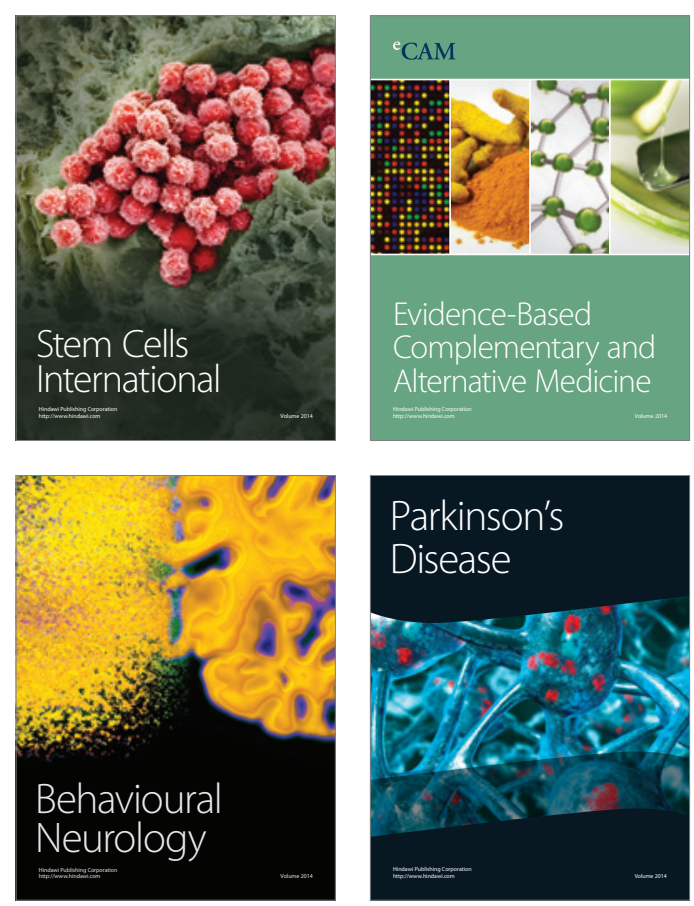

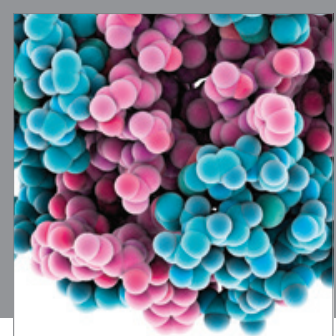

Journal of
Diabetes Research

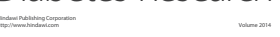

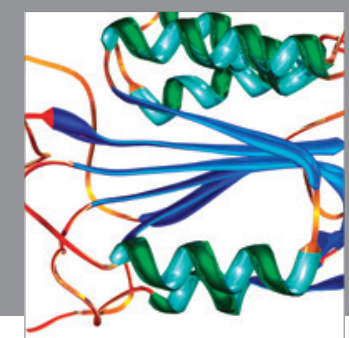

Disease Markers
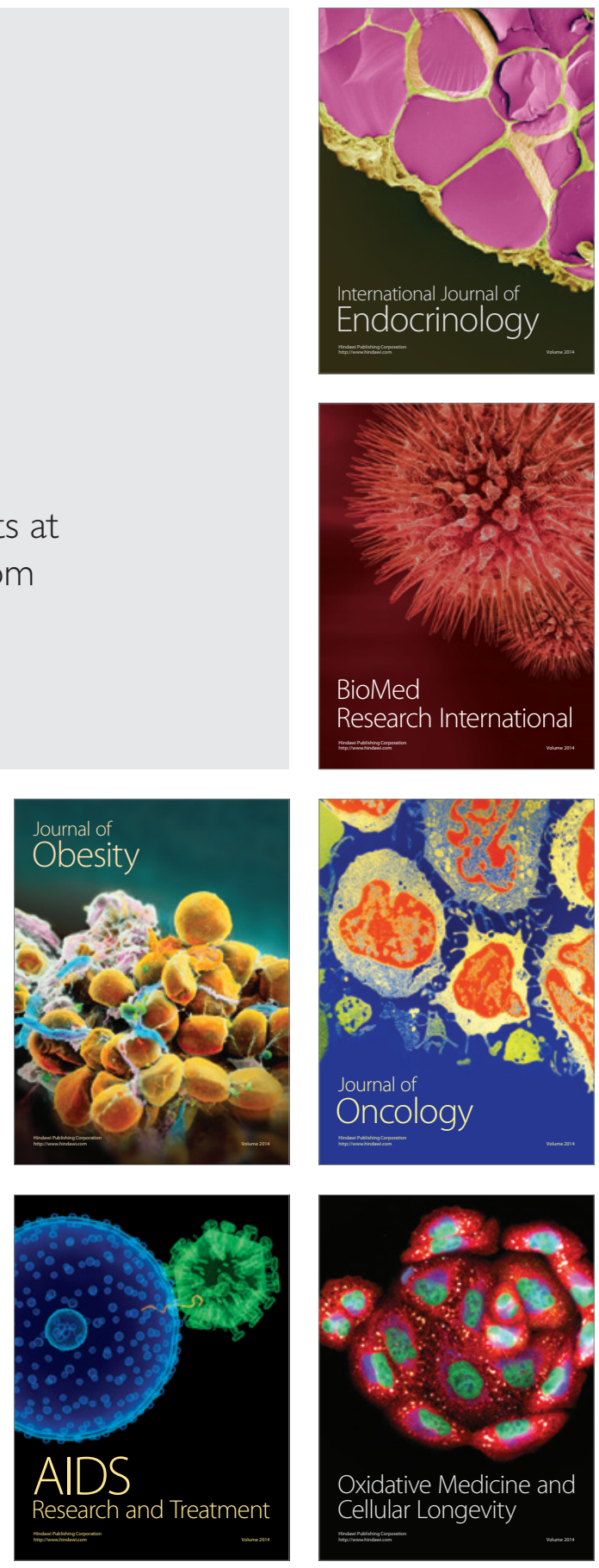